\title{
Evaluation of Regular Insulin Adsorption to Polypropylene Bag and Polyvinyl Chloride Infusion Set
}

\author{
Nursel Sürmelioğlu ${ }^{1}$, Merve Nenni ${ }^{2}$, Ahmet Fırat ${ }^{3}$, Kutay Demirkan ${ }^{4}$, and Dilek Özcengiz ${ }^{3}$ \\ ${ }^{1}$ Cukurova University \\ ${ }^{2}$ Affiliation not available \\ ${ }^{3}$ Faculty of Medicine, Çukurova University \\ ${ }^{4}$ Hacettepe University Faculty of Pharmacy
}

September 21, 2020

\begin{abstract}
Aim Clinical application of insulin infusion therapy is usually accomplished with regular human insulin. It is known that the regular insulin adsorbed to the hydrophobic surfaces and different approaches were implemented into the clinical practices. It was aimed to evaluate the rate of adsorption of insulin to PP bags and PVC infusion sets and stability of insulin during the infusion. Methods $100 \mathrm{IU}$ insulin was added to PP bags containing $100 \mathrm{ml}$ of $0.9 \% \mathrm{NaCl}$ solution(n $=6)$. The infusion was started at a rate of $2 \mathrm{ml} / \mathrm{h}$ using infusion sets in the PVC structure. Insulin quantification was performed in the samples taken both from the bag and from the end tip of the infusion set during infusion. The stability of insulin solutions stored at room $\left(+24^{\circ} \mathrm{C}\right)$ and refrigerator $\left(+4^{\circ} \mathrm{C}\right)$ temperatures were compared. Samples were analyzed using reverse-phase high-performance liquid chromatography. Results No statistically significant difference was found between the concentrations of the samples taken from the bags stored at room and refrigerator temperatures at the 4th, 12th, and 24th hours $(\mathrm{p}>0.05)$. It was seen that the adsorption rate of insulin to PVC set was $57 \%$ and PP bags is at most $5 \%$ at the 24 th hour. Conclusion When PP bags are used for insulin infusion, it is predicted that 24-hour change can be made instead of frequent change. In addition, losses caused by the high rate of insulin adsorption to PVC infusion sets should be considered and PP infusion sets would be the better option to use if available.
\end{abstract}

Evaluation of Regular Insulin Adsorption to Polypropylene Bag and Polyvinyl Chloride Infusion Set

Running Title: Clinical application of insulin infusion

Nursel Sürmelioğlu ${ }^{1}$, Merve Nenni ${ }^{2}$, Ahmet Frrat $^{3}$, Kutay Demirkan ${ }^{4}$, Dilek Özcengiz ${ }^{3}$

${ }^{1}$ Department of Clinical Pharmacy, Faculty of Pharmacy, Çukurova University

${ }^{2}$ Department of Analytical Chemistry, Faculty of Pharmacy, Çukurova University

${ }^{3}$ Department of Intensive Care, Faculty of Medicine, Çukurova University

${ }^{4}$ Department of Clinical Pharmacy, Faculty of Pharmacy, Hacettepe University

Corresponding author

Nursel Sürmelioğlu, PhD

Department of Clinical Pharmacy, Faculty of Pharmacy, Çukurova University, 01380, Sarıçam, Adana, Turkey

Tel: +90-533-054-69-01 
e-mail: nurselisci@gmail.com

Conflict of interest: The authors declare that they have no conflict of interest.

Financial Disclosure : The authors declared that this study has received no financial support.

Author Contributions : N.S and K.D. designed the study and conducted the literature review. M.N. performed the data analysis. All authors interpreted the study data. N.S., M.N. and A.F. wrote the first draft of the manuscript. K.D. and D.Ö. provided critical revisions to the manuscript. All of the authors approved the final version of the manuscript.

Parts of this study were presented in abstract form at the 16. National Internal and Surgical Sciences Intensive Care Congress and 8th Eurasian Intensive Care Meeting, Antalya, Turkey, 13-16 November 2019

\section{Abstract}

\section{$\operatorname{Aim}$}

Clinical application of insulin infusion therapy is usually accomplished with regular human insulin. It is known that the regular insulin adsorbed to the hydrophobic surfaces and different approaches were implemented into the clinical practices. It was aimed to evaluate the rate of adsorption of insulin to PP bags and PVC infusion sets and stability of insulin during the infusion.

\section{Methods}

$100 \mathrm{IU}$ insulin was added to $\mathrm{PP}$ bags containing $100 \mathrm{ml}$ of $0.9 \% \mathrm{NaCl}$ solution $(\mathrm{n}=6)$. The infusion was started at a rate of $2 \mathrm{ml} / \mathrm{h}$ using infusion sets in the PVC structure. Insulin quantification was performed in the samples taken both from the bag and from the end tip of the infusion set during infusion. The stability of insulin solutions stored at room $\left(+24^{\circ} \mathrm{C}\right)$ and refrigerator $\left(+4^{\circ} \mathrm{C}\right)$ temperatures were compared. Samples were analyzed using reverse-phase high-performance liquid chromatography.

\section{Results}

No statistically significant difference was found between the concentrations of the samples taken from the bags stored at room and refrigerator temperatures at the 4 th, 12 th, and 24 th hours $(\mathrm{p}>0.05)$. It was seen that the adsorption rate of insulin to PVC set was $57 \%$ and PP bags is at most $5 \%$ at the 24 th hour.

\section{Conclusion}

When PP bags are used for insulin infusion, it is predicted that 24-hour change can be made instead of frequent change. In addition, losses caused by the high rate of insulin adsorption to PVC infusion sets should be considered and PP infusion sets would be the better option to use if available.

\section{What is already known about this topic?}

- It is known that the regular insulin adsorbed to the surfaces of polyvinyl chloride bags and infusion sets, which are generally used in hospitals, and not to the polypropylene surfaces.

- There are different data about the adsorption rates and approaches were implemented into the clinical practices in the literature.

- There is a lack of information regarding the stability of the insulin solution at room temperature.

\section{What does this article add?}

- As a result of the study, it has been determined that insulin solutions are stable at both room and refrigerator temperatures over $24 \mathrm{~h}$ storage.

- It has been determined that the rate of adhesion of insulin to polyvinyl chloride surface is different from that stated in the literature.

- These results may change the clinical practice.

\section{Introduction}


Hyperglycemia is common in critically ill patients and is a modifiable risk factor that increases morbidity and mortality [1-4]. For many years, optimal treatment of hyperglycemia has been discussed in intensive care units [5]. The American Clinical Endocrinologists Association and the American Diabetes Association recommend keeping glucose levels between $140-180 \mathrm{mg} / \mathrm{dL}$ for glycemic control in critically ill patients [6,7]. In critically ill patients, continuous iv insulin infusion has been shown to be the best route to achieve glycemic targets and prevent glycemic fluctuations [7]. Clinical application of insulin infusion therapy is usually accomplished with regular human insulin $[2,8]$. It is known that the regular insulin adsorbed to the surfaces of polyvinyl chloride (PVC) bags and infusion sets, which are generally used in hospitals, and not to the polypropylene (PP) surfaces. However, there are different data about the adsorption rates in the literature [9-16]. Therefore different approaches were implemented into the clinical practices, such as changing the bag every 4 or 12 hours, to minimize the adsorption of insulin to the bag during the infusion [17-19].

In this study, it was aimed to evaluate the rate of adhesion of insulin solutions to PP bags and PVC infusion sets and stability times at room temperature $\left(+24^{\circ} \mathrm{C}\right)$ during the infusion.

\section{Methods}

Chemicals

İnsulin (Humulin R, Lilly? ${ }^{\text {) }}$, PP bags (Polifarma? ${ }^{\text {) }}$ and PVC infusion sets (Sapphire?) were obtained from a pharmaceutical warehouse. All the chemicals were analytical grade on preparing buffers and solutions. Acetonitrile was purchased from Merck (Darmstadt, Germany). Ultrapure water was purchased from the Milli-Q water system (Barnstead, USA).

\section{Analytical Conditions}

Chromatographic methods for insulin are included in the Turkish Pharmacopoeia [20]. In this study, insulin was analyzed by reverse phase high performance liquid chromatography (RP-HPLC) which the assay was validated according to international guidelines [21]. Briefly, the LC system (Agilent 1220 Infinity II) consisted of a gradient pump, a degasser, and a UV detector (Thermo Separation Products, USA). The separations were achieved by a C18 Phenomenex column $(250 \times 4.6 \mathrm{~mm}, 100 \AA, 5 \mu \mathrm{m}$ i.d.) at room temperature. The mobile phase was acetonitrile:phosphate buffer $(50: 50 \mathrm{v} / \mathrm{v}, \mathrm{pH}: 3.0,10 \mathrm{mM})$ and, solutions delivered at a flow rate of $1 \mathrm{~mL} / \mathrm{min}$ which gave the optimum chromatographic conditions. Injection volume was $20 \mu \mathrm{L}$ and UV detection was performed at $214 \mathrm{~nm}$.

\section{Sample Preparation}

In the study, solutions containing $1 \mathrm{IU} / \mathrm{mL}$ concentration $(\mathrm{n}=6)$ were prepared by adding $100 \mathrm{IU}$ insulin to PP bags containing $100 \mathrm{ml}$ of $0.9 \% \mathrm{NaCl}$ solution. Also, PVC infusion sets were used. In the experimental setup established in accordance with clinical practice, the infusion rate of the solutions was determined as $2 \mathrm{IU} /$ hour through the infusion pump. $600 \mu \mathrm{L}$ samples were taken from the bag at the beginning of the infusion (hour 0), as well as from the bag and at the end tip of the infusion set at the end of the 1st, 2nd, 4th, 12 th and 24th hours. In each sample taken, insulin quantification was made. This experimental procedure was carried out simultaneously with 6 separate insulin solutions prepared at room temperature. As a result of the analysis of the samples taken from each bag and set at specified times, the adsorption rates of insulin to PP bag and PVC infusion set were evaluated.

Also, to evaluate the stability of insulin solutions at room temperature during infusion, the analysis results of samples taken from insulin solutions stored at room $\left(+25^{\circ} \mathrm{C}\right)$ and refrigerator $\left(+4^{\circ} \mathrm{C}\right)$ temperatures at 0 , 4, 12 and 24 hours were compared.

Statistical analysis

Statistical evaluation was performed using Student's t-test and the $p$ values [?]0.05 were considered statistically significant. In the beginning (0 hours), insulin solutions in PP bags are the control group.

\section{Results}


The samples required to evaluate the amount of insulin adsorbed to PP bags were collected simultaneously from 6 separate infusion bags. In the analysis of these samples, the insulin concentration rate of $100 \%$ was accepted at baseline ( 0 hours). The insulin concentration rates of the samples taken from PP bags at the 1st, 2nd, 4th, 12th, and 24th hours of the infusion were determined as 95\%,98\%,98\%,95\%, and 100\%, respectively (Table 1 ).

The samples required to evaluate the amount of insulin adsorbed to the PVC infusion set were collected simultaneously from the end tips of the 6 separate infusion sets. The insulin concentrations of the samples collected at the 1st, 2nd, 4th, 12th, and 24th hours of the infusion were determined as $43 \%, 40 \%, 30 \%, 21 \%$ and $35 \%$, respectively (Table 1 ).

To evaluate the stability of the insulin solution at room temperature, the insulin concentrations of the solutions in PP bags stored at room $(+25 \mathrm{deg}$ C)and at refrigerator $(+4 \mathrm{degC})$ temperatures were compared. The insulin concentration in the PP bag, stored at $+4 \mathrm{deg} \mathrm{C}$, was initially considered $100 \%$ (0 hours). No statistically significant difference was found between the concentrations of the samples taken from the bags stored at room and refrigerator temperatures at the 4th, 12th, and 24th hours ( $>>0.05)$ (Figure 1).

\section{Discussion}

Adsorption is a nonspecific phenomenon that occurs with every solid particle. This phenomenon is particularly important with insulin, because it alters the rate of drug delivery to patient, and finally impacts glycemic control [18]. In order to minimize insulin loss due to adsorption and optimal glycemic control, appropriate clinical practices should be determined according to the rate of insulin adsorbed to the bag and set used during infusion.

In this study, the insulin concentration rates of the samples taken from PP bags at the 1st, 2nd, 4th, 12th, and 24th hours were determined as 95\%, 98\%, 98\%, 95\%, and 100\%, respectively. Accordingly, it has been shown that the rate of insulin adsorption to PP bags is at most $5 \%$, and this rate decreases after the first hour of infusion. In a study by Jakobson et al. it was shown that insulin adsorbed $10 \%$ to the PP bag at the first hour of infusion, and then this rate was decreased while insulin was administered at a rate of $1 \mathrm{ml} / \mathrm{h}$. Similarly, the maximum adsorption rate was achieved at the 1st hour and then reduction was determined in both studies [10]. The difference between the maximum adsorption rates is thought to result from the difference in infusion rates. It is reported that the rate of adsorption increases with a slower infusion rate [10,16-22].

The insulin concentration of the samples taken from the end tip of the PVC infusion set, at the 1st, 2nd, 4 th, 12th, and 24th hours were detected as $43 \%, 40 \%, 30 \%, 21 \%$ and $35 \%$, respectively. Accordingly, it was seen that the adsorption rate of insulin to PVC set was $57 \%$ at the 1 st hour and $65 \%$ at the 24 th hour. In the study conducted by Zahid et al., it was shown that the adsorption rate of insulin to the PVC neonatal tube was approximately $55 \%$ at 3 hours and $15 \%$ at 24 hours [16]. It is thought that the high adsorption rate determined in our study may be due to the surface area difference of the sets used in both studies. In the study of Trissel et al., it was reported that the 24-hour adsorption rate of insulin to the PVC bag was 35\%. However, in Trissel's study, the sample was taken from the PVC bag at the beginning and after 24 hours storage, not during infusion [15]. Although the methods of both studies are different, it has been shown that the maximum adsorption rate was within the first 4 hours and then reduction in this rate was detected. So, changing the bag every 4 hours, which is frequently applied in clinical practice, leads to an increase in insulin loss.

It is thought that changing PVC and PP bags every 24 hours is more appropriate in terms of both preventing insulin loss and reducing workload. Besides, economic advantages of changing insulin solution bag every 24 hours versus 4 hours should be considered in terms of minimization of manpower (time spend for administration frequency and preparation), sources (bag and solution) and insulin loss. However, the stability of the insulin solution is of concern when using the bags for 24 hours. Also, there is no information on the stability of the insulin solution at room temperature in the package insert. As a result of the analysis, the insulin solution has been shown to maintain its stability for 24 hours at room temperature. 


\section{Conclusion}

As a result of the study, it has been determined that insulin solutions are stable at both room and refrigerator temperatures over $24 \mathrm{~h}$ storage. When PP bags are used for insulin infusion, it is predicted that 24-hour change can be made instead of frequent change. In addition, losses caused by the high rate of insulin adhesion to PVC infusion sets should be considered and PP infusion sets would be the better option to use if available.

\section{References}

1. Bagshaw SM, Hoste EA, Jacka MJ. Best evidence in critical care medicine. Intensive vs conventional blood glucose control in critically ill patients. Can J Anaesth. 2010; 57: 172-5.

2. Van den Berghe G, Wouters P, Weekers F, Verwaest C, Bruyninckx F, Schetz M, Vlasselaers D, Ferdinande P, Lauwers P, Bouillon R. Intensive insulin therapy in the critically ill patients. N Engl J Med. 2001; 345: 1359-67.

3. Capes SE, Hunt D, Malmberg K, Gerstein HC. Stress hyperglycaemia and increased risk of death after myocardial infarction in patients with and without diabetes: a systematic overview. Lancet. 2000; 355: $773-8$.

4. Bistrian BR. Hyperglycemia and infection: which is the chicken and which is the egg? JPEN J Parenter Enteral Nutr. 2001; 25: 180-1.

5. Coşkun R, Gündoğan K, Güven M, Sungur M. Efficacy of an insulin infusion treatment protocol administered in a medical intensive care unit. J Crit Intensive Care. 2012; 1: 9-12.

6. Qaseem A, Chou R, Humphrey LL, Shekelle P, Clinical Guidelines Committee of the AmericaN College of P. Inpatient glycemic control: best practice advice from the Clinical Guidelines Committee of the American College of Physicians. Am J Med Qual. 2014; 29(2): 95-8.

7. American Diabetes Associadion. Diabetes care in the hospital: standards of medical care in diabetes2019. Diabetes Care. 2019; 42(Suppl 1): 173-81.

8. Bilotta F, Badenes R, Lolli S, Belda FJ, Einav S, Rosa G. Insulin infusion therapy in critical care patients: regular insulin vs short-acting insulin. A prospective, crossover, randomized, multicenter blind study. J Crit Care . 2015; 30(2):437.e1-6.

9. Doglietto GB, Bellantone R, Bossola M, Perri V, Ratto C, Pacelli F, Crucitti F. Insulin adsorption to three-liter ethylen vinyl acetate bags during 24-hour infusion. JPEN J Parenter Enteral Nutr. 1989; 13(5): 539-41.

10. Jakobsson T, Shulman R, Gill H, Taylor K. The impact of insulin adsorption onto the infusion sets in the adult intensive care unit. J Diabetes Sci Technol. 2009; 3(1): 213-4.

11. Ng KX, Yeo JHT, Woo FZ, Wong JPY, Sethi SK, Loh TP. Insulin adsorption by infusion sets in the setting of treatment of hyperkalaemia. Wien Klin Wochenschr. 2016; 128(11-12): 460-1.

12. Peterson L, Caldwell J, Hoffman J. Insulin adsorbance to polyvinylchloride surfaces with implications for constant-infusion therapy. Diabetes. 1976; 25(1): 72-4.

13. Petty C, Cunningham NL. Insulin adsorption by glass infusion bottles, polyvinylchloride infusion containers, and intravenous tubing. Anesthesiology. 1974; 0(4): 400-4.

14. Thompson CD, Vital-Carona J, Faustino EVS. The effect of tubing dwell time on insulin adsorption during intravenous insulin infusions. Diabetes Technol Ther. 2012; 4(10): 912-6.

15. Trissel LA, Xu QA, Baker M. Drug compatibility with new polyolefin infusion solution containers. Am J Health Syst Pharm. 2006; 63(23), 2379-82.

16. Zahid N, Taylor KM, Gill H, Maguire F, Shulman R. Adsorption of insulin onto infusion sets used in adult intensive care unit and neonatal care settings. Diabetes Res Clin Pract. 2008; 80(3): e11-e13.

17. Goldberg PA, Kedves A, Walter K, Groszmann A, Belous A, Inzucchi SE. "Waste Not, Want Not": Determining the Optimal Priming Volume for Intravenous Insulin Infusions. Diabetes Technol Ther. $2006 ; 8(5): 598-601$.

18. Kalra S, Bajwa SJ. Intravenous insulin use: technical aspects and caveats. JPMA. 2013; 63(5): 650-3.

19. Turner RE. Insulin administration for the control of blood glucose in the adult ICU-an evidence-based guideline: guideline. SAJCC. 2007; 23(1): 24-30.

20. Turkish Pharmacopoeia. Turkish Medicines and Medical Devices Agency; Place, 2017. 
21. Guideline IHT. (2005). Validation of analytical procedures: text and methodology. Q2 (R1). 2005; 1: $1-15$.

22. Fuloria M, Friedberg MA, DuRant RH, Aschner JL. Effect of flow rate and insulin priming on the recovery of insulin from microbore infusion tubing. Pediatrics. 1998; 102(6): 1401-6.

\section{Hosted file}

Table 1.docx available at https://authorea.com/users/360538/articles/482190-evaluation-ofregular-insulin-adsorption-to-polypropylene-bag-and-polyvinyl-chloride-infusion-set

\section{Hosted file}

Figure 1.docx available at https://authorea.com/users/360538/articles/482190-evaluation-ofregular-insulin-adsorption-to-polypropylene-bag-and-polyvinyl-chloride-infusion-set 